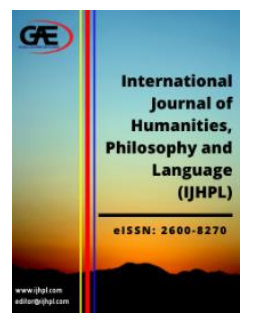

International Journal of Humanities, Philosophy and Language (IJHPL)

\title{
COMPARATIVE STUDY ON MYTH BETWEEN CHINESE AND ARABIC: PHOENIX AS AN EXAMPLE
}

\author{
Ye Xinyu $^{1 *}$, Associate Prof. Muhammad Anas AL-Muhsin²
}

1 Department of Modern language, Universiti Penidikan Sultan Idris, Malaysia Email: m20182001728@siswa.upsi.edu.my

2 Department of Modern language, Universiti Penidikan Sultan Idris, Malaysia Email: anas@fbk.upsi.edu.my

Corresponding Author

\section{Article Info:}

\section{Article history:}

Received date: 09.03.2020

Revised date: 09.04.2020

Accepted date: 12.04 .2020

Published date: 10.06.2020

\section{To cite this document:}

Xinyu, Y., \& Al-Muhsin, M. A. (2020). Comparative Study on Myth Between Chinese and Arabic: Phoenix as An Example. International Journal of Humanities, Philosophy and Language, 3 (10), 12-17.

DOI: $10.35631 /$ IJHPL.310002.

\begin{abstract}
:
The myth of a nation reflects the collective memory of the nation and is the source of the philosophy, religion, and literature of the nation. Since the 1930s, mythological research has gradually emerged in China, but there are few comparative studies on Chinese and Arab mythology. Comparative study on myth between Chinese and Arabic: Phoenix as an example in terms of social values and national traits. This article is based on the specific exploration of the mythical image of Phoenix. The records of the Arab world for the phoenix are derived from some ancient Arabic books and this research on Arab mythology starts with basic old books and expands the research materials on Arab mythology. Therefore, providing more research texts for foreign Arab mythological researchers becomes the core task in this article. Under the background of the current research, we seek an updated perspective to focus on the imagery problems in Arab Chinese mythology, especially the image of Phoenix, not only for ancient China and Arab mythology. Research work injects new power, and more importantly, enriches the study of folk literature. This article introduces the meaning of mythology and carries out preliminary preparations such as text analysis, theoretical study, and translation tools, and also discusses the inheritance and development of Chinese Arab folk culture. Folk culture is the foundation of a nation's development. The writing of phoenix in Chinese mythology is an important part of ancient Chinese folk culture. Similarly, it is also important for Arab mythology. In short, the high and profound cultural endogenous and national spiritual connotations of myths better realize the function of cultivating their national spirit.
\end{abstract}

Keywords:

Myth, Phoenix, Chinese Traditional Culture, Arabic Traditional Culture 


\section{Introduction}

For the generation of myths, people believe that in the primitive era, low levels of productivity limited people's knowledge. When they struggle with nature, it is impossible to understand nature and master it. Therefore, the forces of change in nature are attributed to the will and strength of God. They believe that these unpredictable phenomena are guided and controlled by God. Therefore, in their minds, all the natural forces and their imagined personalities are conceived. Later, when making works, they created many stories about God based on their heroic personality. They spread in words, which is the origin of myth.

Chinese Arabian mythology has a long history and is worth living alone in the study of Chinese Arabian social history. According to the functionalist mythology school, mythology plays an irreplaceable role in the development of social culture. As a special reflection of social reality and belief, it also plays an important role in the actual life of the ancestors, and at the same time, it is the mean to answer individuals and society confuse and maintain social harmony. The British anthropologist John Wickley believes that mythology has no specific theoretical significance in primitive society, nor is it that science has yet to discover the understanding of the world by the predecessors. The existence of myths has a purely practical function (Wickley, 1995). The role of myth is to deepen the meaning and value of tradition while giving it value and authority to ensure the effectiveness of rituals and social customs, including guidance on the scale of human behavior.

The myth of "death and resurrection" is the research object of this article, it is a group of quite vivid myths in the mythological system. Its basic core is concentrated on the performance of "life", "death" and "love". The mythical archetypes are repeatedly sung in later narrative literature, gradually superimposed into tradition in collective memory, and become an important force of culture and identity. This is the value of mythology. The Phoenix is a very important image in the myth of death and resurrection. It is widely believed that Phoenix must have been an abstract symbol of primitive people expressing their lives. These symbols are extracted from different animals, plants or organisms without thinking, similar to the reality of some birds. It simply replicates and restores future generations based on their observations and opinions, which he calls "naturalization." The Phoenix model is not this or a type of bird, but it is only a symbol of divine power. It maintains an understanding of the external primitives and the desire to control the world with symbols.

Compared with the phoenix connotation in Chinese traditional culture, Arabian phoenix emphasizes the beautiful side of its rebirth and resurrection. In Arabian mythology, the phoenix has the reputation of "immortal bird" and "long-lived bird" and is a symbol of "live forever and never die". The phoenix is also the symbol of the anthropomorphic image of chastity. Despite the different lengths of its rebirth, early Christian art and literature regarded it as a symbol of resurrection, immortality, and rebirth.

\section{Statement Of The Problem}

Mythology is a very important carrier for us to study ancient folk literature. It is the product of cultural consciousness in the historical development of all ethnic groups and affects the spiritual and civilized life of modern people. The representative image of the myth of Phoenix is important in the history of mythology. The phoenix originated from the Arabian Peninsula in Western mythology. In Chinese mythology, the image of the phoenix began from the Yellow Emperor era. The Arab nation has the oldest and longest recorded of the phoenix. Therefore, based on the existing research, it is necessary for us to systematically and profoundly study the myths of China and Arabia. 
For Chinese mythology, previous research has left more space for development, diverse images, and functions. It is our understanding of the life and history of the Chinese nation. Compared with the study of Chinese mythology, the development of Arabian mythology has not been studied due to religious reasons. The study of mythology is still concentrated in the period before the Arab Islamic civilization. And the information of that era can only find a very small part of it. In the study of mythology in the Arab world, we have encountered many difficulties. The records of the phoenix are derived from some ancient Arabic books, which are difficult to read, and the information that can be found is very small. This article's research on Arab mythology starts with basic old books and expands the research materials on Arab mythology. Therefore, providing more research texts for foreign Arab mythological researchers has become the core task of this research

\section{Research Question}

What is the significance of the myth about Phoenix in Chinese and Arab mythology?

\section{Significance of The Study}

Myth is the unity of primitive consciousness, which integrates the philosophy, science, history, and literature of primitive people. Therefore, mythology has always been an important part of literary, philosophical, and historical studies. Connorton, the master of American mythology, believes that the wisdom of primitive people and ancient people are reflected in mythology. But modern people do not know the goods, blindly abandon these myths. If these myths can be correctly understood, modern people can be freed from spiritual distress (Connorton, 2000). The famous anthropologist John Wickley believes that mythology is important for the consolidation and enhancement of traditional culture (John Wickley, 1995).

Mythological thinking is symbolic or metaphorical thinking. The symbol, metaphor is the connection between a specific object and a certain meaning. The characteristics of primitive thinking determine that primitive people can't use independent ideas to think independently, but with the development of culture, trace history, exchange ideas, sum up experience, express beliefs often involve some abstract ideas. Therefore, they must borrow certain concrete objects to suggest certain similar or related concepts. It can be said that the original mythology is composed of these different types of symbolic and metaphorical image symbol systems.

The famous Swiss psychologist Benedict R said that a person who speaks with the original image speaks with the voice of millions of people at the same time. He turned our destiny into the destiny of mankind. He awakened those benevolent forces to us. It is these forces that ensure that human beings can get out of danger and spend the night. This is the power of mythology (Benedict R, 1961). It can be said that mythological thinking is an educational image of the natural and human destiny that the original ancestors tried to show us. It is a key for humans to understand themselves.

\section{Literature Review}

Humans usually worship birds in the Neolithic period. Archaeologist Cao Shunqing proposed the concept of "divine civilization" and the concept of "bird goddess" in response to the myth of prehistoric beliefs in Eurasia for 10,000 (Cao Shunqing, 2002). Come to God after entering into the history of civilization, the global goddess of the prehistoric bird era was revived and re-modeled in the traditions of different regions of the world, forming the worship of colorful birds and legends. Chinese ancestors also favored a long-tailed bird among all birds, and that was the Chinese phoenix, Fenghuang. Arguably this is one of the largest inventions of local myths after the Dragon Fairy. 
From the source's point of view, the phoenix is not only a certain type of bird but a symbolic symbol. To result in the elimination of reality, the perception of the outside world, and the externalization of its power. Creating this kind of emotion is not enough to express the animal; it is a conveyor of collective consciousness. As Mark said: "The real tendency of the ancient civilized will is to seek the abstraction of uncertain elements that make the outer body relatively close (Mark Gerrard, 2002).

Therefore, the phoenix should originally be an abstract symbol of primitive people's expression of their own lives. These symbols are extracted from various animals, plants or organisms without thinking, their similarity with the reality of some birds. It is only to reproduce and restore future generations according to their observations and perceptions, which Winser calls "naturalization". In Jiang Tingting's view, the phoenix model is not a bird of this kind, but an abstract symbol representing a kind of divine power (Jiang Tingting, 2006). It carries people's primitive understanding of the outside world and the desire to dominate the world with symbols. In the process of later conclusion, the phoenix became into all kinds of sun goddess, beautified and honored, the phoenix that we now see.

In short, Phoenix is an early totem in China and even in the world. It is a mere symbol that cherishes the understanding of primitive people and their desire for the outside world and themselves, and the primitive people give it in their imagination. Phoenix Nirvana became the carrier of the dead and revived the prototype today.

Phoenix is considered a people's imagination in China. Xiangtao offers that from ancient times to the present, the phoenix began with a simple prototype, and the shape of the length of the birds, after a multi-level transformation, the ideal image of agility and luxury today. In long evolution and change, the image of Phoenix is characterized by unique innovation in every historical period (Xiangtao, 2018). The process of its composition is the process of collecting the factors of "beauty", "of life higher than life", or "of natural things higher than natural things", infiltrate, permeate, express the mythical conjecture of our people, worship of nature and religious fitness, aesthetic happiness and artistic taste.

\section{Methodology}

Comparative literature is a literary study based on cross-ethnic, cross-linguistic, cross-cultural and inter-disciplinary perspectives. In the establishment of disciplines, the comparative perspective of the subject is the ontological body of the study, thus emphasizing the positioning of the research subject. Comparative literature positions the research object of the discipline in three relationships between national ethnic literature and literature and other disciplines: factual material relations, aesthetic value relations, and interdisciplinary relationships.

Through parallel research and comparative methodology, Chinese and Arabic literature can dialectic and analyze representative achievements, summarize the critical results, which not only effectively promote the construction of Chinese Arab culture research methods, but also provide effective ways for comparative literature theory innovation. The mythological image of Chinese classics is selected as the research object, the parallel comparison method is used to explore Chinese Arabic literature.

Using various differences as a clue to compare the differences between Chinese and Arab cultures, Arab culture focuses on the complementarity of opposites, the emphasis on words over sound, the way of thinking is focused on intuitive rather than logical; and the emphasis on the logic of thinking in Chinese culture is the coexistence of words and sounds, the resonance 
caused by it is enough to make the perspective between language, culture, and thinking enter the path of the comparative field of Chinese and Western culture. By comparing the specific propositions or interpretation frameworks in parallel research methods, it is found that there are differences in the meaning of words expression in Arab studies in Chinese culture.

\section{Conclusion}

The revival, and transformation of the goddess birds in the world mythology, as well as the colorful bird legends and the long-tailed birds in all birds that Chinese ancestors liked, is called the Phoenix. It can be said that it is a more important image in the world's myths and legends. Therefore, Phoenix must have been an abstract symbol of primitive people expressing their lives. These symbols are extracted from different animals, plants or organisms without thinking, similar to the reality of some birds.

In short, Phoenix is an early totem in China and the world. It is a symbol that prides itself on the primitive people's understanding and desire for the outside world and themselves, while the primitive people give it a vivid image in their imagination. The magical ritual is the basis of the original form. The Phoenix Resurrection Ceremony lost its true character in the long history of development. Legends and myths have become miserable and beautiful.

The mythical image of the Phoenix has far-reaching influence. There are many places in the world named after the Phoenix. At the same time, Phoenix is also of great significance to the creation of later world literature. We can often see the word phoenix in Arabic poetry. The poets used the beautiful image of the phoenix to express their emotions, which made the literature reach a new height. In China, the phoenix has become the highest compliment in interpersonal communication because the phoenix has been portrayed as a deadly bird in the mythical story.

\section{References}

Abrams, M. H. (2005). Glossary of literary terms. Beijing: Beijing University.

Benedict R. (1961). Patterns of Culture. Boston: Houghton Mifflin Company.

Campo, Aitor Freen. (2018). Phoenix in Roman thought. Spain: University of Salamanca editions.

Cao Shunqing. (2002). Comparative Literature Theory. Chengdu: Sichuan Education Press.

Gao Youpin. (2019). Regarding the Chinese creation myth, there are several issues of primitive worship. Wuhan: Journal of Renmin University of China.

Jiang Tingting. (2006). Phoenix and Phoenix Nirvana - the legend of the resurrection through time and space. Nanjing: Jilin Normal University Journal (Humanities and Social Sciences).

Li Aiqin, Wang Yingchun. (2016). The Differences between Creation Myths and the Traditional Ways of Thinking between Chinese and Western Peoples. Guizhou: Guizhou Research on Ethnic Minorities.

Liu Shuangshuang. (2012). A Comparative Study of Female Images in Chinese Mythology and Greek Mythology. Shijiazhuang: Hebei University.

John Wickley. (1995). Myths and Literature. (Pan Guoqing, et al. Translation). Shanghai: Shanghai Literature and Art Publishing House.

Mark Gerrard. (2002). Understanding Myth in Postmodern Culture: Driving the Journey. France: University of Pennsylvania Press.

Paul Connorton. (2000). How does society remember. (Nazi Biligo, translated.Hai). Shanghai: People's Publishing House.

Wu Yanrong. (2018). The origin of the Phoenix (bird) ascension. China: Social Science Trends. 
Xinag Tao. (2008). History of Western 20th Century Literary Theory. Beijing: Peking University Press.

Yuan Xiuping. (2017). A Comparative Study of Chinese and Western Creation Myths. Mudanjiang: Journal of Mudanjiang University.

Zhao Yifan. (2013). Keywords in Western literary theory. Beijing: Foreign Language Teaching and Research Publishing House. 